\title{
Variance component estimates applying random regression models for test-day milk yield in Caracu heifers (Bos taurus Artiodactyla, Bovidae)
}

\author{
Lenira El Faro ${ }^{1}$, Vera Lucia Cardoso ${ }^{1}$ and Lucia Galvão de Albuquerque ${ }^{2}$ \\ ${ }^{1}$ Agência Paulista de Tecnologia dos Agronegócios, Secretaria da Agricultura e Abastecimento, \\ Ribeirão Preto, SP, Brazil. \\ ${ }^{2}$ Departamento de Zootecnia, Faculdade de Ciências Agrárias e Veterinárias, \\ Universidade Estadual Paulista "Júlio de Mesquita Filho”, Jaboticabal, SP, Brazil.
}

\begin{abstract}
Random regression models (RRM) were used to estimate covariance functions for 2,155 first-lactation milk yields of native Brazilian Caracu heifers. The models included contemporary group (defined as year-month of test and paddock) fixed effects, and quadratic effect of age of cow at calving. Genetic and permanent environmental effects were fitted by a random regression model and Legendre polynomials of days in milk (DIM). Schwarz's Bayesian information criteria (BIC) indicated that the best RRM assumed a six coefficient function for both random effects and a sixth order variance function for residual structure. Akaike's information criteria suggested a model with the same number of coefficients for both effects and a residual structure fitted by a step function with 15 variances. Phenotypic, additive genetic, permanent environmental and residual variances were higher at the beginning and declined during lactation. The RRM heritability estimates were 0.09 to 0.26 and generally higher at the beginning and end of lactation. Some unexpected negative genetic correlations emerged when higher order covariance functions were used. A model with four coefficients for additive genetic covariance function explains more parsimoniously the changes in genetic variation with DIM since the genetic parameter was more acceptable and BIC was close to that for a six coefficient covariance function.
\end{abstract}

Key words: covariance functions, dairy cattle, genetic parameters, longitudinal data, milk yield.

Received: June 27, 2007; Accepted: January 23, 2008.

\section{Introduction}

In animal husbandry, repeated measurements of the same individual have been analyzed using several different approaches, with repeatability models and test-day models (TDMO) using univariate or multivariate analyses having been the customary approach to model such measurements. More recently, however, instead of the traditional cumulative 305-day analysis random regression models (RRM) have been used as an alternative for the genetic evaluation of dairy cattle.

The use of RRM allow fitting individual random lactation curves as deviations of a mean trend, using ordinary polynomials or other linear functions. In addition, they permit the estimation of (co)variance structures between different tests using covariance functions. Covariance functions, proposed by Kirkpatrick et al. (1990) for the analysis of longitudinal data (for example, growth or lactation mea-

Send correspondence to Lenira El Faro. Secretaria da Agricultura e Abastecimento, Av. Bandeirantes 2419, 14030-640 Ribeirão Preto, SP, Brazil. E-mail: lenira@apta.sp.gov.br. surements), are equivalent to covariance matrices for the multivariate models of finite dimension. What makes covariance functions interesting is their ability to describe gradual changes in covariances over time, and to estimate punctual variances and covariances along a trajectory, even if little or no information between points is available.

With RRM, it is possible to produce estimated breeding values (EBVs) for the lactation curves of each animal and for the components of the curves such as lactation persistency (Ptak and Schaeffer, 1993; Jamrozik and Schaeffer, 1997). This might be important when selecting animals from breeds with low lactation persistency, such as Zebu (Bos indica) or native breeds, as well as crossbreds.

In general, RRM heritability estimates are higher than those obtained by TDMO, indicating higher genetic variability both at the beginning and at the end of the lactation. Some authors have reported overestimation of heritability or unexpected genetic correlations between test day milk yields (TDMY) at different stages of lactation using RRM (Jamrozik and Schaeffer, 1997; Jamrozik et al., 1997a,b; Brotherstone et al., 2000; Kettunen et al., 2000). 
In Brazil and most Latin America countries, milk production is based on crossbred cows resulting from the mating of Zebu or native breed cows with bulls of specialized European breeds. The Caracu breed is considered to be a native Brazilian breed originating from Iberian cattle brought to Brazil during colonization but, however, estimates of covariance function for the milk yield of Zebu and Brazilian native cattle breeds are not frequent.

The objective of the study described in this paper was to estimate additive genetic and permanent environmental covariance functions for Caracu TDMY using RRM with different residual variances structures.

\section{Material and Methods}

In this study we used information collected from a 2,500 head herd of Caracu cattle of all age categories held at Recreio Farm in the municipality of Poços de Caldas in the southeastern Brazilian state of Minas Gerais (MG). The farm had 14 paddocks, where cows were allocated according to lactation stage and production level. Cows were milked by hand, twice a day, in the presence of the calf. One quarter was left for feeding the calf during the whole lactation period. During the rainy season (October to May), cows were kept on pastures, receiving corn silage supplementation during the dry season. All cows received concentrate supplementation after milking. A breeding season was adopted and cows were submitted to natural mating during April to February. Up to 1995 heifers were mated at two years of age and a body weight of $300 \mathrm{~kg}$ to $400 \mathrm{~kg}$, but after 1995 the first mating was at 17 months and a body weight of $350 \mathrm{~kg}$.

We analyzed 86,698 weekly records from 2,155 first-lactation heifers recorded between 1978 and 1998. There were from 6 to 43 TDMY per lactation and over 94\% of the lactations had at least 35 tests. Days in milk ranged from 5 days to 305 days and were grouped into 43 weekly classes. The average age at first calving was 35.68 months, with a standard deviation of 4.06 months.

Univariate RRM were used to estimate covariance functions for TDMY. The additive genetic and permanent environmental effects were modeled by polynomials on a Legendre scale with functions ranging from 4 to 6 coefficients. The model included fixed effects of contemporary group and linear and quadratic effects of calving age. The population mean trend was modeled by a four coefficient cubic regression on the Legendre polynomial of days in milk based on the smallest mean square errors after adjusting functions from 2 to 5 coefficients. There were 1,582 contemporary groups, defined as year-month of record and paddock. Temporary environmental effects were assumed to be independently distributed, with heterogeneous residual variances modeled by a step function with 15 classes $\left(\sigma_{\text {ei }}^{2}, i=1,15\right)$, or by a sixth order ordinary polynomial variance function. Classes of residual variances were: 1, 2, 3,
4-5, 6-7, 8-9, 10-11, 12-13, 14-16, 17-25, 26-30, 31-35, $36-38,39-42$ and 43 weeks of lactation, based on a previous study (El Faro and Albuquerque, 2003).

The general random regression model can be represented as:

$$
y=X b+Z a+W c+e
$$

where $y=$ vector of $N$ observations, measured in $N_{d}$ recorded animals; $b=$ vector of fixed effects; $a=$ vector of solutions for additive genetic random coefficients; $c=$ vector of solutions for permanent environmental random coefficients; $e=$ vector of $\mathrm{N}$ different residuals; $X, Z, W=$ incidence matrices for fixed and additive genetic and permanent environmental random effects, respectively.

The assumptions with respect to the components of the model were:

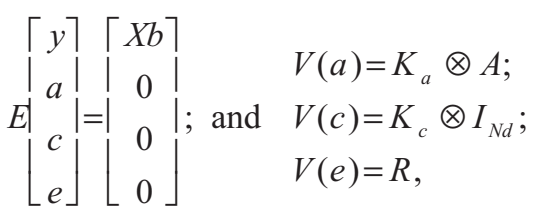

where $K_{a}$ and $K_{c}$ are the genetic and permanent environmental covariance matrices between random regression coefficients, respectively. A is the additive genetic relationship matrix; $I_{N d}$ is an identity matrix of dimension $N_{d}$, and $R$ represents a diagonal matrix containing the residual variances. For days in milk ti and tj, standardized to the interval -1 to 1 , the genetic $(\mathrm{G})$ and permanent environmental $(\mathrm{C})$ covariances between test-day milk yields were estimated by

$$
G=\left(\begin{array}{llll}
1 & t_{i} & t_{i}^{2} & \ldots
\end{array}\right) K_{a}\left[\begin{array}{c}
1 \\
t_{j} \\
t_{j}^{2} \\
\ldots
\end{array}\right]
$$

and

$$
C=\left(\begin{array}{llll}
1 & t_{i} & t_{i}^{2} & \ldots
\end{array}\right) K_{c}\left[\begin{array}{c}
1 \\
t_{j} \\
t_{j}^{2} \\
\ldots
\end{array}\right]
$$

When the structure of residual variances were fitted by variance function, the variances were estimated by:

$$
V_{e_{i}}^{2}=V_{e_{0}}^{2}\left(1+\sum_{r=1}^{q} \beta_{r} t_{i j}^{r}\right)
$$

$V_{e_{0}}^{2}$ corresponds to variance intercept, $\beta_{r}$ are the $q$ regression coefficients of VF and $t_{i j}$ are weeks of lactation.

The additive genetic eigenvalues with small variations were set to an operational zero $\left(10^{-18}\right)$, forcing estimates of the $K_{a}$ matrix to have a reduced rank $(m)$. The number of additive genetic coefficients to be estimated was 
reduced from $k(k+1) / 2$ coefficients to $k m-m(m-1) / 2$ coefficients, with $k=$ order of the polynomial function (Meyer, 1998b).

Variance components were estimated by the restricted maximum likelihood method (REML) using the DXMRR program from the DFREML package (Meyer, 1998a). Standard univariate analysis considering a finite dimension model (TDMO) was carried out for 21 TDMY (Table 1), with a univariate animal model containing the contemporary groups, age of cow (linear and quadratic) and days in milk (linear) as fixed effects and additive genetic as random effect. Variance components were estimated by the restricted maximum likelihood method (REML) using MTDF package (Boldman et al., 1995).

The RRM, with different orders of fit, were compared by Akaike's information criterion (AIC) and Schwarz's Bayesian information criterion (BIC) (Wolfinger, 1993; Nunez-Antón and Zimmerman, 2000), both of which impose penalties according to the number of parameters to be estimated.

Ten different RRM were compared to identify the best order of covariance functions for additive genetic and permanent environmental effects and for residual structures of variances. The number of covariance function coefficients was denoted respectively, as $k_{a}$ and $k_{c}$, for genetic and permanent environmental random effects. For both effects, the number of coefficients ranged from 4 to 6 . The residual variances were denoted $\mathrm{vf6}$, for the variance function or $\mathrm{c} 15$ for a step function with fifteen classes.

\section{Results and Discussion}

The overall TDMY mean $5.09 \mathrm{~kg}$ with a standard deviation of $2.30 \mathrm{~kg}$. The number of records decreased as lactation progressed and larger variations in milk yields were observed at the end of lactation (Table 1).

Modeling the residual variances by a step function with 15 classes (c15) instead of a sixth order variance function (vf6) increased the $\log$-likelihood function ( $\log \mathrm{L}$ ) and AIC decreased, independent of the other components in the model (Table 2). However, in general, the BIC results favored the variance function model, probably because this criterion attributes a more stringent penalty for the number of parameters to be estimated.

Changing the number of coefficients of genetic and permanent environmental covariance functions from 4 (cubic) to 6 (quintic) increased $\log \mathrm{L}$ (Table 2). For AIC, the best fit model had $\mathrm{k}_{\mathrm{a}}=6, \mathrm{k}_{\mathrm{c}}=6$ and a step function with 15 classes of residual variances (model 10) and 57 parameters to be estimated. However, the BIC results indicated that a model with $\mathrm{k}_{\mathrm{a}}=6, \mathrm{k}_{\mathrm{c}}=6$ and a variance function (model 9) with 49 parameters to be estimated was sufficient to adequately model the covariance structures. Based on LRT, reducing the rank of $\mathrm{k}_{\mathrm{a}}$ from 6 to 5 or 4 (not shown) did not significantly affect $\log$ L. López-Romero and Carabaño (2003) also found that BIC results favored less parame-
Table 1 - Days in milk, number of records, overall means and standard deviations of test-day milk yields (TDMY) for the univariate model.

\begin{tabular}{|c|c|c|c|}
\hline Week & Day in milk & Number of records & Mean $\pm \mathrm{SD}(\mathrm{kg})$ \\
\hline 2 & $12-18$ & 2059 & $7.25 \pm 2.53$ \\
\hline 4 & $26-32$ & 2076 & $7.42 \pm 2.51$ \\
\hline 6 & $40-46$ & 2087 & $7.18 \pm 2.34$ \\
\hline 8 & $54-60$ & 2092 & $6.99 \pm 2.09$ \\
\hline 10 & $68-74$ & 2120 & $6.68 \pm 1.98$ \\
\hline 12 & $82-88$ & 2129 & $6.30 \pm 1.89$ \\
\hline 14 & $96-102$ & 2130 & $5.80 \pm 1.77$ \\
\hline 16 & $110-116$ & 2138 & $5.42 \pm 1.69$ \\
\hline 18 & $124-130$ & 2142 & $5.09 \pm 1.63$ \\
\hline 20 & $138-144$ & 2132 & $4.93 \pm 1.60$ \\
\hline 22 & $152-158$ & 2130 & $4.76 \pm 1.59$ \\
\hline 24 & $166-172$ & 2137 & $4.60 \pm 1.56$ \\
\hline 26 & $180-186$ & 2135 & $4.46 \pm 1.55$ \\
\hline 28 & $194-200$ & 2134 & $4.32 \pm 1.55$ \\
\hline 30 & $208-214$ & 2136 & $4.15 \pm 1.57$ \\
\hline 32 & $222-228$ & 2121 & $3.97 \pm 1.59$ \\
\hline 34 & $236-242$ & 2099 & $3.69 \pm 1.61$ \\
\hline 36 & $250-256$ & 2026 & $3.41 \pm 1.60$ \\
\hline 38 & $264-270$ & 1875 & $3.16 \pm 1.56$ \\
\hline 40 & $278-284$ & 1614 & $2.96 \pm 1.49$ \\
\hline 42 & $299-305$ & 1235 & $2.76 \pm 1.40$ \\
\hline
\end{tabular}

terized models, and those considering orders from 2 to 3 for $\mathrm{k}_{\mathrm{a}}$ and 5 to 6 for $\mathrm{k}_{\mathrm{c}}$, with homogeneity of residual variances, were indicated.

The structure of residual variances (vf6 or c15) did not affect the partition of variances for models 9 and 10 . The variance of intercept was 0.656 and the coefficients of variance functions for residual structure were, -0.577 , $1.288,-0.279,-1.154,-0.621$ and 0.973 , respectively, for linear to 6 th order. No differences in residual variance estimates were observed between these models (Figure 1).

\section{Covariance component and heritability estimates}

Genetic covariance estimates (not shown) between TDMY, at the beginning and the end of lactation, obtained by the two best RRM models based on BIC, were negative. Moreover, the genetic covariance surfaces estimated with these models were not smooth. It has been found that higher order polynomials usually produce "wiggly" functions (Kirkpatrick et al., 1990 and Meyer, 1998b). An alternative less parameterized model was used to compare the trends in parameters. It was observed that a model considering $\mathrm{k}_{\mathrm{a}}=4$, $\mathrm{k}_{\mathrm{c}}=6$ and a variance function for residuals (model 3) had BIC values slightly higher than model 9 and did not show 
Table 2 - Order of fit for additive genetic $\left(\mathrm{k}_{\mathrm{a}}\right)$ and permanent environmental $\left(\mathrm{k}_{\mathrm{c}}\right)$ effects and residual structures $(\mathrm{r})$, number of parameters $(\mathrm{Np})$, log likelihood function ( $\log \mathrm{L})$, Akaike's information criterion (AIC) and Bayesian information criterion (BIC).

\begin{tabular}{|c|c|c|c|c|c|c|c|}
\hline \multirow[t]{2}{*}{ Model } & \multicolumn{3}{|c|}{ Order of fit } & \multirow[t]{2}{*}{$\mathrm{Np}$} & \multirow[t]{2}{*}{$\log \mathrm{L}$} & \multirow[t]{2}{*}{$\mathrm{AIC} *$} & \multirow[t]{2}{*}{$\mathrm{BIC} *$} \\
\hline & $\mathrm{k}_{\mathrm{a}}$ & $\mathrm{k}_{\mathrm{c}}$ & $\mathrm{r}$ & & & & \\
\hline 1 & 4 & 4 & vf6 & 27 & -98551.35 & 98605.35 & 98858.31 \\
\hline 2 & 4 & 4 & 15 & 35 & -98415.48 & 98485.48 & 98813.39 \\
\hline 3 & 4 & 6 & vf6 & 38 & -96066.02 & 96142.02 & 96498.04 \\
\hline 4 & 4 & 6 & 15 & 46 & -95984.61 & 96076.61 & 96507.58 \\
\hline 5 & 5 & 6 & vf6 & 43 & -96042.03 & 96128.03 & 96530.90 \\
\hline 6 & 5 & 6 & 15 & 51 & -95963.34 & 96065.34 & 96543.16 \\
\hline 7 & 5 & 5 & vf6 & 37 & -97111.16 & 97185.16 & 97531.81 \\
\hline 8 & 5 & 5 & 15 & 45 & -97037.18 & 97127.18 & 97548.78 \\
\hline 9 & 6 & 6 & vf6 & 49 & -95911.43 & 96009.43 & 96468.51 \\
\hline 10 & 6 & 6 & 15 & 57 & -95835.91 & 95949.91 & 96483.95 \\
\hline
\end{tabular}

* Values in boldface type indicate the best models.

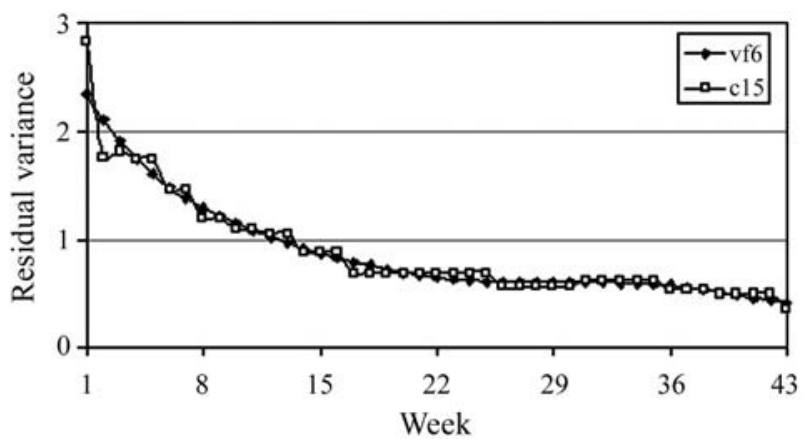

Figure 1 - Residual variances estimated by variance function (vf6) or step function (c15).

negative covariance estimates or "wiggly" surface. Results will be presented and compared for model 9 and model 3 .

Phenotypic, additive genetic, permanent environmental and residual variances were higher at the beginning of lactation, decreasing thereafter. For RRM, residual plus permanent environmental variances $\left(\sigma_{\mathrm{e}}^{2}+\sigma_{\text {ap }}^{2}\right)$ were presented and compared with residual variances for standard univariate model (TDMO). When analyzing standard univariate models, the environmental variances are not split in permanent and temporary. Therefore, to compare estimates obtained from the three models, the environmental temporary and permanent variances obtained from RRM were summed (Figure 2). Phenotypic variances $\left(\sigma_{\mathrm{p}}^{2}\right)$ estimated either by RRM or by standard univariate analysis were similar. In relation to $\sigma_{\mathrm{e}}^{2}+\sigma_{\text {ap }}^{2}$ for MRA and to $\sigma_{\mathrm{e}}^{2}$ for TDMO, a similar behavior was observed for the variances. Genetic variance estimates obtained with both RRM $(4,6, \mathrm{vf6}$ and $6,6, \mathrm{vf} 6)$ were similar and close to those obtained by univariate analysis. In general, the variance estimates were higher at the beginning of the lactation and decreased thereafter, with exception of genetic variance estimates which slightly increased at the end of lactation.
Heritability estimates obtained with the two RRM $(4,6, \mathrm{vf6}$ and $6,6, \mathrm{vf} 6)$ and by univariate analysis are presented in Figure 3. The heritability estimates obtained with the TDMO ranged from $0.09\left(12^{\text {th }}\right.$ week $)$ to $0.32\left(42^{\text {nd }}\right.$ week), with higher estimates at the end of lactation, probably due to the lower number of records at these points. Heritabilities estimated by the $6,6, \mathrm{vf} 6$ model ranged from 0.09 to 0.26 , while those estimated by the $4,6, \mathrm{vf} 6$ model ranged from 0.09 to 0.21 . For both RRM, the estimates were lower during mid-lactation, from $14^{\text {th }}$ to $30^{\text {th }}$ week. In general, RRM heritability estimates were similar to those obtained by TDMO, with larger differences in test day milk yields around $14^{\text {th }}$ to $28^{\text {th }}$ weeks. The estimates obtained by 6,6 ,vf6 model oscillated more than those from 4,6,vf6 model, with higher heritabilities observed at the extremes of lactation. Trends of the heritability estimates, obtained by RRM, followed those reported in the literature, i.e., higher estimates at the beginning and towards the end of lactation (Strabel and Misztal, 1999; Tijani et al., 1999; Brotherstone et al., 2000). Difficulties to model the variances at the extremes of lactation can be explained, in part, by the biological processes that occur at the beginning of lactation and the smaller number of records at the end. For Zebu and tropical native breeds, both reasons can be even more important. In general, these animals have not been as intensively selected for milk production as Holsteins and population sizes are smaller. It is usually necessary to keep the calf with the dam during milking and short lactations are frequent.

Due to the high order of genetic covariance function $\left(\mathrm{k}_{\mathrm{a}}=6\right)$, oscillations in heritability estimates were observed along the trajectory. Although the estimates obtained by standard univariate analysis had shown a similar pattern for the heritabilities at the end of lactation, like the RRM with $\mathrm{k}_{\mathrm{a}}=6$, a less parameterized model for additive genetic effect, e.g. 4,6,vf6 model seems to be more consistent biologically. 

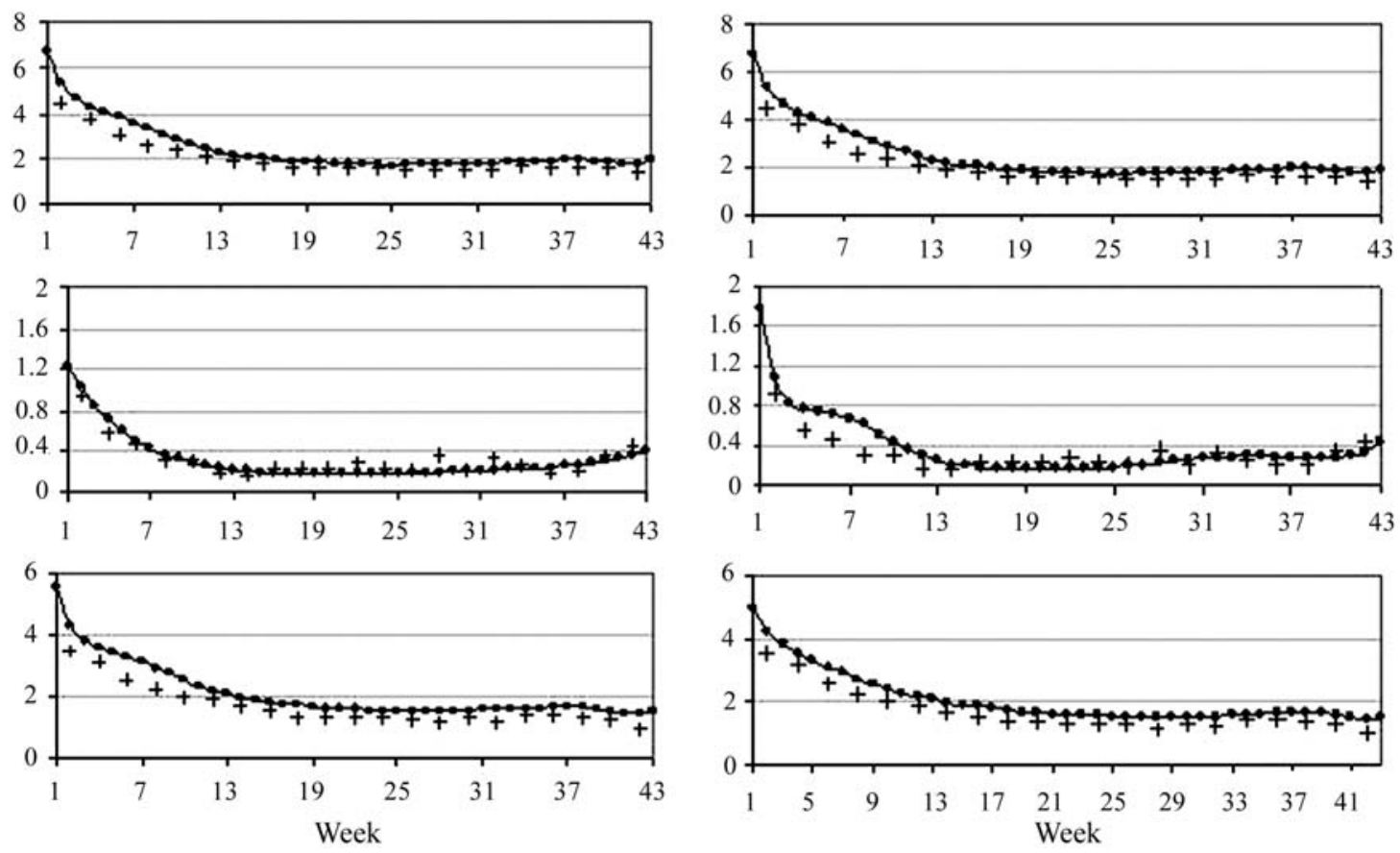

Figure 2 - Phenotypic (top), genetic (middle) and environmental (bottom) variance estimates from 4,6,vf6 (left) and 6,6,vf6 (right) random regression and standard univariate $(+)$ analysis.
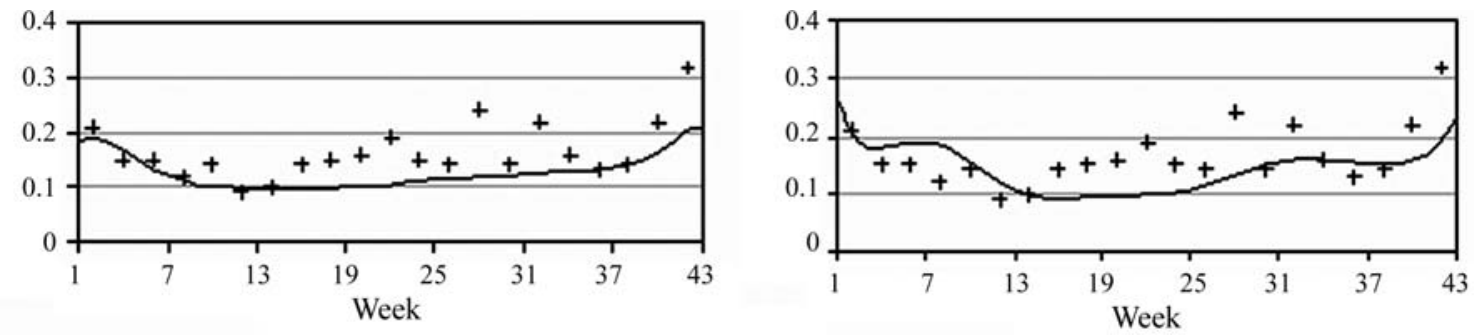

Figure 3 - Heritability estimates by 4,6,vf6 (left) and 6,6,vf6 (right) random regression and standard univariate analysis (+).

The magnitude of heritability estimates in the present study was smaller than those reported for European breed cows in Brazil (Melo et al., 2005 and Cobuci et al., 2005) and in temperate regions (Jamrozik and Schaeffer, 1997; Jamrozik et al., 1997a,b; Olori et al., 1999). Jamrozik and Schaeffer (1997), using the parametric function described by Ali and Schaeffer (1987), obtained heritability estimates ranging from 0.40 to 0.59 , with higher values during the first ten days of lactation. Olori et al. (1999), using RR on orthogonal polynomials of days in milk with orders varying from three to five, estimated heritabilities ranging from 0.22 to 0.52 . They also found that, in general, TDMY at the end of lactation (around the $35^{\text {th }}$ week) were more heritable than those obtained at earlier stages.

Regarding Zebu breeds, e.g. Gyr, heritability estimates have been higher than those obtained for Holstein cattle. Costa et al. (2005) presented estimates ranging from 0.71 at the earlier to 0.27 at the end of lactation.

\section{Correlation estimates}

Phenotypic correlation estimates ranged from 0.09 to 0.77 and were very close for both RRM $(4,6, \mathrm{vf6}$ and $6,6, \mathrm{vf} 6)$. The estimates were higher between adjacent records (Figure 4). Other authors have reported the same trend, with positive estimates that are higher between closer productions (Lidauer et al., 2003; Mayeres et al., 2004). As expected, permanent environmental correlation estimates obtained with both models were similar, since both had the same order of fit, and ranged from 0.25 to 0.99 (Figure 5). Some oscillations were observed in surfaces for both RRM, although a smoother pattern had been expected. In general, genetic correlations were higher than permanent environmental and phenotypic correlations, but estimates decreased more drastically with the increase in days between records.

Some differences in genetic correlation estimates were observed between models (Figure 6). Genetic correlations for the 6,6,vf6 model were not as smooth as those 

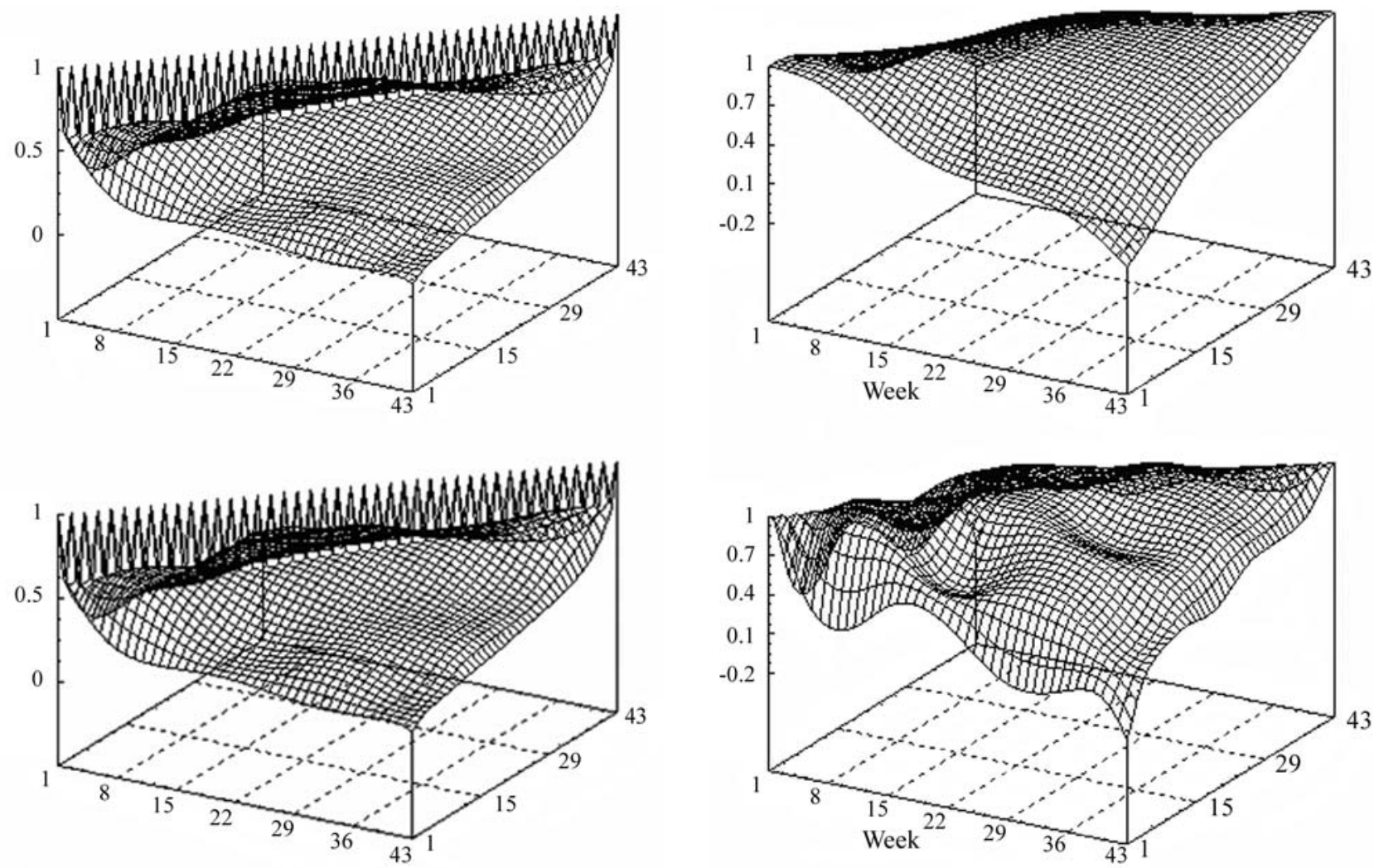

Figure 4 - Estimates of phenotypic correlations between TDMY obtained with 4,6,vf6 (above) and 6,6,vf6 (bellow) random regression models.

obtained by the 4,6,f6 model, probably because of the higher order polynomial used for $\mathrm{k}_{\mathrm{a}}$ in the first model. It is to be expected that a higher order polynomial is more flexible, following the changes of (co)variances with age more closely and producing "wiggly" surfaces (Meyer, 1998b). In general, genetic correlation estimates were higher between adjacent tests, decreasing markedly with the increase of test intervals. Estimates ranged from -0.15 to 0.99 for the 6,6 , vf6 model and from 0.03 to 0.99 for the 4,6,vf6 model. Irrespectively of the residual variance structure, vf6 or c15, negative genetic correlations were observed between tests at the beginning and at the end of lactation with the model with $k_{a}=6$. These estimates may suggest over-parameterization of these RRM. The estimates for 4,6,vf6 random regression model were similar to those obtained with the dimension finite model, whose genetic correlation ranged from 0.2 to 1.0 , and seem to be more acceptable.

Negative genetic correlations between yields during early and late lactation were also obtained by Brotherstone et al. (2000), using parametric functions to fit RRM, such as Wilmink and Ali and Schaeffer functions, for Holstein TDMY. López-Romero and Carabaño (2003) pointed out that these parametric functions tend to overestimate the genetic variances and underestimate the genetic correlations between milk yield at the beginning and the end of lactations. Probably this is also truth for

Figure 5 - Estimates of genetic correlations between TDMY obtained with 4,6,vf6 (above) and 6,6,vf6 (bellow) random regression models.

Legendre polynomials. Those authors also found that high order Legendre polynomials produced "wiggly" functions, with variance patterns different from those at expected in biological processes.

Estimates of (co)variances and correlations between random regression coefficients for 4,6,vf6 and 6,6,vf6 models are presented in Table 3. For both models the most variable coefficient was the intercept. The correlation between fourth and fifth additive genetic random regression coefficients was high and negative, resulting in an eigenvalue close to zero for the fifth coefficient, for the $6,6, \mathrm{vf} 6$ model. Independently of the model, the correlations between all permanent environmental coefficients were of low magnitude. In both the 4,6,vf6 and 6,6,vf6 models, permanent environmental coefficient matrix eigenvalues were higher than those of the additive genetic effect. These results could justify higher orders for permanent environmental covariance functions than for additive genetic, as also reported by other authors (Brotherstone et al., 2000; Pool et al., 2000; López-Romero and Carabaño, 2003). López-Romero and Carabaño (2003) reported that increasing the order of fit for the permanent environmental effect resulted in a clear improvement of statistics employed in the model comparison. However, when increasing the order of fit for the additive genetic effect, the model improvement was smaller. Similar results have also been reported for 

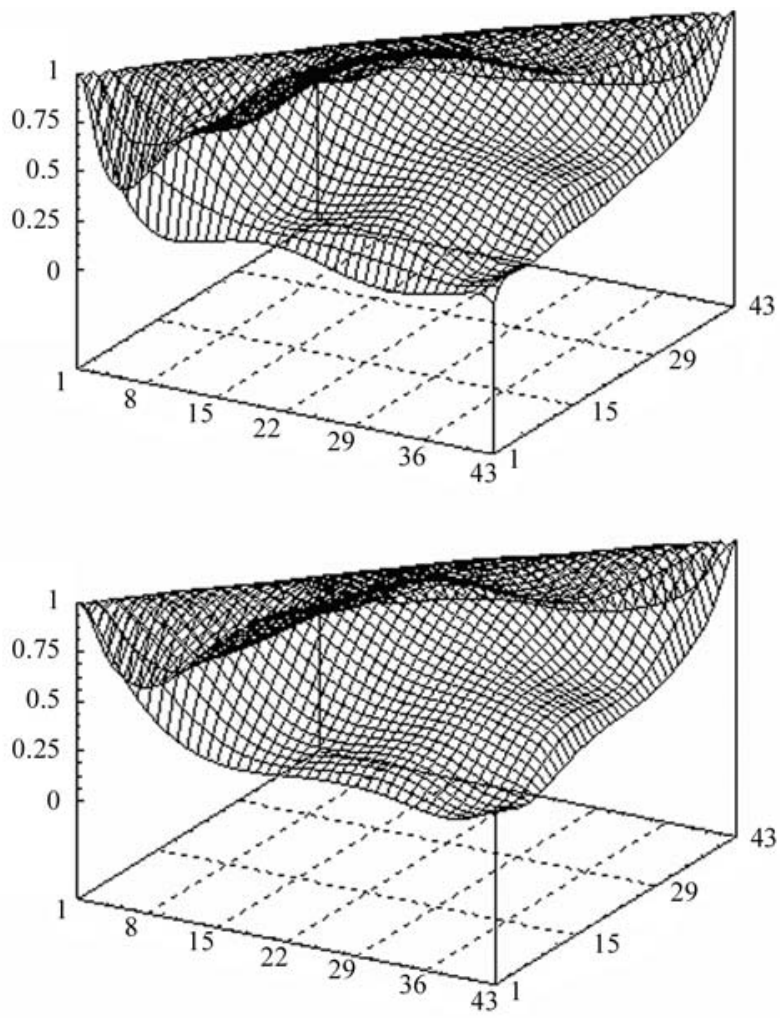

Figure 6 - Estimates of permanent environmental correlations between TDMY obtained with 4,6,vf6 (above) and 6,6,vf6 (bellow) random regression models.

Holstein cows (López-Romero and Carabaño, 2003). A similar trend has also been reported for growth traits (Meyer, 1998b; Albuquerque and Meyer, 2001). For both random effects, the highest variations were associated with the first and second eigenvalues (Table 3 ). For both the 4,6,vf6 and 6,6,vf6 models the first three eigenvalues of the additive genetic covariance function accounted for about $96 \%$ of the sum of all eigenvalues. These values are similar to those reported by Pool et al. (2000), with the first three eigenvalues explaining $98 \%$ of the total genetic variation. In our study, the leading eigenvalue accounted for $70 \%$ $(6,6, \mathrm{vf} 6 \mathrm{model})$ and $73 \%(4,6, \mathrm{vf} 6$ model $)$ of the sum of all eigenvalues. These results suggest that a reduced rank model or a $\mathrm{k}_{\mathrm{a}}$ with smaller order could be used.

The additive genetic eigenfunctions for the 4,6,vf6 model are shown in Figure 7. The same pattern of additive genetic eigenfunctions was observed for the $6,6, \mathrm{vf} 6$ random regression model. The main eigenfunction, corresponding to the largest eigenvalue, provided only positive values along the trajectory and did not show any large changes during lactation. The major part of the observed genetic variance can be explained by a factor which is practically constant throughout lactation, suggesting that if selection were based on any TDMY genetic gains would be obtained for all periods. A similar pattern was also obtained
Table 3 - Estimates of variances (diagonal, boldface type), covariances (lower diagonal) and correlations (upper diagonal) between random regression coefficients and eigenvalues $(\lambda)$ for additive genetic effects and permanent environmental effects based on the coefficient matrices for two models, one with an order of fit of $6,6, \mathrm{vf} 6\left(\mathrm{k}_{\mathrm{a}}=6, \mathrm{k}_{\mathrm{c}}=6\right)$ and a variance function for residuals (model 10) and the other with an order of fit of 4,6 , vf6 $\left(\mathrm{k}_{\mathrm{a}}=4, \mathrm{k}_{\mathrm{c}}=6\right)$ and a variance function for residuals (model 3$)$. The abbreviations $k_{a}$ and $k_{c}$ are the genetic and permanent environmental covariance matrices between random regression coefficients respectively, while $\mathrm{vf}$ is the variance function.

\begin{tabular}{|c|c|c|c|c|c|c|}
\hline \multicolumn{7}{|c|}{ Model with $6,6, \mathrm{vf} 6$ order of fit } \\
\hline & \multicolumn{6}{|c|}{ Random regression coefficients } \\
\hline Eigenvalues $(\lambda)$ & 0 & 1 & 2 & 3 & 4 & 5 \\
\hline \multicolumn{7}{|c|}{ Additive genetic effect } \\
\hline 0.5044 & 0.4758 & -0.26 & 0.40 & -0.27 & -0.34 & 0.26 \\
\hline 0.1347 & -0.0665 & 0.1334 & -0.58 & 0.53 & 0.03 & -0.08 \\
\hline 0.0183 & 0.0517 & -0.0393 & 0.0348 & -0.53 & 0.05 & 0.004 \\
\hline 0.0086 & -0.0238 & 0.0246 & -0.0126 & 0.0162 & -0.33 & 0.58 \\
\hline 0.0652 & -0.0476 & 0.0025 & 0.0018 & -0.0085 & 0.0404 & -0.90 \\
\hline 0.0000 & 0.0312 & -0.0052 & 0.0001 & 0.0129 & -0.0318 & 0.0306 \\
\hline \multicolumn{7}{|c|}{ Permanent environmental effect } \\
\hline 1.5163 & 1.5052 & -0.13 & -0.04 & -0.01 & -0.17 & -0.05 \\
\hline 0.4001 & -0.0984 & 0.3617 & -0.29 & -0.06 & 0.15 & -0.43 \\
\hline 0.1867 & -0.0249 & -0.0799 & 0.2122 & -0.19 & -0.20 & 0.10 \\
\hline 0.1177 & -0.0046 & -0.0119 & 0.0279 & 0.1052 & -0.29 & -0.31 \\
\hline 0.0564 & -0.0567 & 0.0239 & -0.0253 & -0.0260 & 0.0754 & -0.11 \\
\hline 0.0195 & -0.0116 & -0.0500 & 0.0087 & -0.0192 & -0.0059 & 0.0369 \\
\hline \multicolumn{7}{|c|}{ Model with 4,6,vf6 order of fit } \\
\hline & \multicolumn{6}{|c|}{ Random regression coefficients } \\
\hline Eigenvalues $(\lambda)$ & 0 & 1 & 2 & 3 & 4 & 5 \\
\hline \multicolumn{7}{|c|}{ Additive genetic effect } \\
\hline 0.4566 & 0.4358 & -0.23 & 0.40 & -0.34 & & \\
\hline 0.1422 & -0.0565 & 0.1388 & -0.58 & 0.64 & & \\
\hline 0.0196 & 0.0496 & -0.0413 & 0.0360 & -0.56 & & \\
\hline 0.0076 & -0.0282 & 0.0297 & -0.0131 & 0.0154 & & \\
\hline \multicolumn{7}{|c|}{ Permanent environmental effect } \\
\hline 0.4012 & -0.1056 & 0.3596 & -0.29 & -0.08 & 0.14 & -0.37 \\
\hline 0.1872 & -0.0234 & -0.0799 & 0.2119 & -0.18 & -0.15 & 0.08 \\
\hline 0.0864 & -0.0032 & -0.0158 & -0.0275 & 0.1063 & -0.31 & -0.09 \\
\hline 0.1360 & -0.0924 & 0.0288 & -0.0237 & -0.0333 & 0.1111 & -0.42 \\
\hline 0.0287 & 0.0157 & -0.0573 & 0.0098 & -0.0074 & -0.0365 & 0.0668 \\
\hline
\end{tabular}

by Olori et al. (1999), with the leading eigenvalue accounting for $93 \%$ of total variation.

The second eigenfunction was associated with an eigenvalue of 0.142 , corresponding to $23 \%$ of the total genetic variation. The corresponding eigenfunction was negative up to the $13^{\text {th }}$ week and positive during later weeks. This indicates an antagonistic relationship between initial 


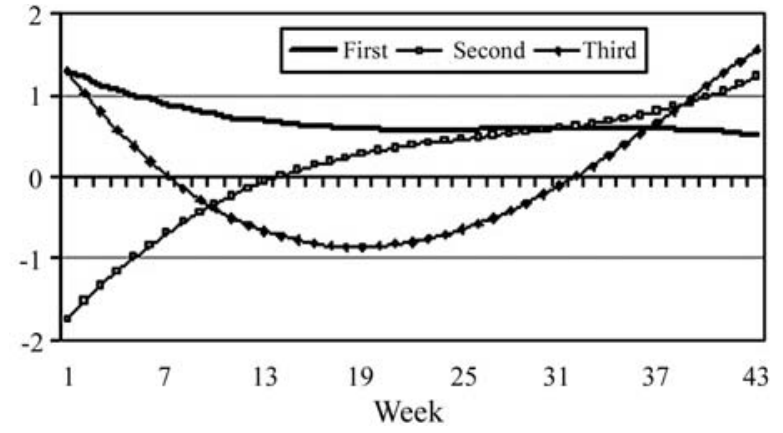

Figure 7 - Additive genetic eigenfunctions estimated by 4,6,vf6 random regression model.

milk yields (up to 13 weeks) and milk yields during the remaining lactation period. The third eigenfunction indicates a positive and favorable relationship between yields up to the $9^{\text {th }}$ week and from the $32^{\text {nd }}$ week on, and an unfavorable relationship with mid-lactation yields. Changes in sign observed for the $2^{\text {nd }}$ and $3^{\text {rd }}$ eigenfunctions suggest the existence of factors with contrasting effects between stages of lactation, but they account for a small proportion of the additive genetic variance. Although eigenfunctions can identify the most probable changes in the trajectory of lactation, selection based on these components or on canonic variables is still uncertain.

The difficulties of establishing criteria for the choice of the best RRM are evident in our study. In principle, the $\mathrm{AIC}$ and BIC tests were regarded as being sufficient for selection, but, in fact, the estimates of genetic parameters also proved to be helpful. The literature shows that, in general, the choice of models are based either on AIC or BIC, with preference being given to the BIC results because they are more rigorous concerning the number of parameters in the model. In our study, the BIC test indicated that the $6,6, \mathrm{vf} 6$ model was the best. Negative genetic covariances between TDMY, however, could suggest an overparameterization of the model for the additive effect since a model with a smaller order of $\mathrm{k}_{\mathrm{a}}$ did not produce the same negative estimates, therefore providing a more parsimonious fit. We expected to obtain covariance or correlation structures describing smoother patterns for the surfaces, but this was not observed for the additive genetic effect when $\mathrm{k}_{\mathrm{a}}$ was equal to six coefficients (Figure 4). In previous studies using the same data set and applying standard bivariate analyses, El Faro and Albuquerque (2003) did not observe negative genetic correlation estimates between test day yields.

During the lactation trajectory we observed oscillations in heritability estimates due to the high order of genetic covariance function $\left(\mathrm{k}_{\mathrm{a}}=6\right)$. Although the estimates obtained by standard univariate analysis showed patterns similar to those obtained by the RRM with $\mathrm{k}_{\mathrm{a}}=6$ at the end of lactation, a less parameterized model (e.g., the 4,6,vf6 model) for additive genetic effect provided lower estimates at the extremes and seems to be biologically more consis- tent. Unlike the univariate estimates, which were highest at mid-lactation, the RRM heritability estimates were generally higher at the extremes of the lactation curves. The beginning of lactation is marked by biological processes which are difficult to model, a fact emphasized by the higher residual variances estimated by us during this period. However, fewer records are available at the end of lactation for Zebu and Caracu animals due to shorter lactation and management decisions. This is a problem yet to be solved in the application of random regression models.

Although the use of RRM in dairy cattle breeding has been questioned (Druet et al., 2005; Strabel et al., 2005; Strabel and Jamrozik, 2006) the possibility of estimating breeding values for milk persistency is an undeniable advantage of this methodology (Schaeffer, 2004). In tropical countries, milk production is largely based on Zebu cattle and their crosses or tropical native breeds characterized by low persistency of lactation, this methodology represents an important tool for the improvement of milk production. The application of these models in animal breeding programs has proved to be feasible as they already have being implemented in some countries (Schaeffer, 2004).

Based on the absence of interference of the structure of residual variances (step function or variance function) on genetic parameters, and on BIC test results, we concluded that a model with residual variances function would be sufficient to model such structure. Despite the fact that the AIC and BIC tests indicated that a RRM with six additive genetic and permanent environmental coefficients would be the most adequate, the genetic parameters estimated for the best model according to these tests suggest that overparameterization for the additive genetic effect may have occurred. A model with four coefficients for additive genetic covariance function seems to be sufficient to explain more parsimoniously the changes in genetic variation with days in milk.

\section{Acknowledgments}

The authors thank the Recreio farm, in special Mr. Andre Stein Carvalho Dias, for providing the data and Dr Karin Meyer for helping in the beginning of this work. We gratefully acknowledge the Conselho Nacional de Pesquisa Científica (CNPq), Brazil, for the first authors' scholarship.

\section{References}

Albuquerque LG and Meyer K (2001) Estimates of covariance functions for growth from birth to 630 days of age in Nelore cattle. J Anim Sci 79:2776-2789.

Ali TE and Schaeffer LR (1987) Accounting for covariances among test day milk yields in dairy cows. J Anim Sci 67:637-644.

Boldman KG, Kriese LA, Van Vleck LD, Van Tassel CP and Kachman SD (1995) A Manual for Use of MTDFREML. A Set of Programs to Obtain Estimates of Variances and Covariances [DRAFT]. USDA-ARS, Clay Center, 114 pp. 
Brotherstone S, White IMS and Meyer K (2000) Genetic modeling of daily yield using orthogonal polynomials and parametric curves. J Anim Sci 70:407-415.

Cobuci JA, Euclydes RF, Lopes OS, Costa CN, Torres RA and Pereira CS (2005) Estimation of genetic parameters for test-day milk yield in Holstein cows using a random regression model. Genet Mol Biol 28:75-83.

Costa CN, Melo CM, Machado CH, Freitas AF, Packer IU and Cobuci JA (2005) Parâmetros genéticos para a produção de leite de controles individuais de vacas da raça Gir estimados com modelos de repetibilidade e regressão aleatória. Rev Bras Zootec 34:1519-1530.

Druet T, Jaffrézic F and Ducrocq V (2005) Estimation of genetic parameters for test day records of dairy traits in the first three lactations. Genet Sel Evol 37:257-271.

El Faro L and Albuquerque LG (2003) Estimação de parâmetros genéticos para produção de leite no dia do controle e para a produção acumulada em até 305 dias para primeiras lactações de vacas da raça Caracu. Rev Bras Zootec 32:284-294.

Jamrozik J and Schaeffer LR (1997) Estimates of genetic parameters for a test day model with random regressions for yield traits of first lactation Holsteins. J Dairy Sci 80:762-770.

Jamrozik J, Kistemaker Gj, Dekkers JCM and Schaeffer LR (1997a) Comparison of possible covariates for use in a random regression model for analyses of test day yields. J Dairy Sci 80:2550-2556.

Jamrozik J, Schaeffer LR, Liu L and Jansen G (1997b) Multiple trait random regression test day model for production traits. In: Proc $16^{\text {th }}$ Interbull Meeting, Vienna, pp 43-47. http:// www-interbull.slu.se/bulletins/bulletin16/Jamrozik.pdf (January, 2008).

Kettunen A, Mäntysaari EA and Pösö J (2000) Estimation of genetic parameters for daily milk yield of primiparous Ayrshire cows by random regression test-day models. Livestock Prod Sci 66:251-261.

Kirkpatrick M, Lofsvold D and Bulmer M (1990) Analysis of the inheritance, selection and evolution of growth trajectories. Genetics 124:979-993.

Lidauer M, Mantysaari EA and Stranden I (2003) Comparison of test-day models for genetic evaluation of production traits in dairy cattle. Livestock Prod Sci 79:73-86.

López-Romero P and Carabaño MJ (2003) Evaluating alternative random regression models to analyse first lactation daily milk yield data in Holstein-Friesian cattle. Livestock Prod Sci 82:81-96.
Mayeres P, Stoll J, Bormann J, Reents R and Gengler N (2004) Prediction of daily milk, fat, and protein production by a random regression test-day model. J Dairy Sci 87:1925-1933.

Melo CMR, Costa CN, Packer IU and Machado PF (2005) Parâmetros genéticos para as produções de leite do dia do controle e da primeira lactação de vacas da raça holandesa. Rev Bras Zootec 34:796-806.

Meyer K (1998a) DXMRR - A program to estimate covariance functions for longitudinal data by REML. In: Proc. $6^{\text {th }}$ World Congr Genet Appl Livest Prod, Armidale, Australia, v. 27, pp 465-466.

Meyer K (1998b) Estimating covariance functions for longitudinal data using a random regression model. Genet Sel Evol 30:221-240.

Nunez-Antón VN and Zimmerman DL (2000) Modeling nonstationary longitudinal data. Biometrics 56:699-705.

Olori VE, Hill WG, Mcguirk BJ and Brotherstone S (1999) Estimating variance components for test day milk records by restricted maximum likelihood with a random regression animal model. Livestock Prod Sci 61:53-63.

Pool MH, Janss LLG and Meuwissen THE (2000) Genetic parameters of Legendre polynomials for first parity lactation curves. J Dairy Sci 83:2640-2649.

Ptak E and Schaeffer LR (1993) Use of test day yields for genetic evaluation of dairy sires and cows. Livestock Prod Sci 34:23-34.

Schaeffer LR (2004) Application of random regression models in animal breeding. Livestock Prod Sci 86:35-45.

Strabel T and Jamrozik J (2006) Genetic analysis of milk production traits of Polish Black and White cattle using large-scale random regression test-day models. J Dairy Sci 89:31523163.

Strabel T and Misztal I (1999) Genetic parameters for first and second lactation milk yields of Polish Black and White cattle with random regression test-day models. J Dairy Sci 82:2805-2810.

Strabel T, Szyda J, Ptak J and Jamrozik J (2005) Comparison of random regression test-day models for Polish Black and White cattle. J Dairy Sci 88:3688-3699.

Tijani A, Wiggans GR, Van Tassel CP, Philpot JC and Gengler N (1999) Use of (co)variance functions to describe (co)variances for test day yield. J Dairy Sci 82(supplement):226.

Wolfinger R (1993) Covariance structure selection in general mixed models. Commun Statist 22:1079-1106.

Associate Editor: Pedro Franklin Barbosa

License information: This is an open-access article distributed under the terms of the Creative Commons Attribution License, which permits unrestricted use, distribution, and reproduction in any medium, provided the original work is properly cited. 